\title{
Anesthesia for cesarean in pregnant with uncorrected failot tetralogy
}

\begin{abstract}
Tetralogy of Fallot is the most common cyanotic congenital heart disease. Hemodynamic changes can cause serious and fatal multi-organ complications, the choice of anesthesia is very difficult.Combined spinal epidural techniques have become an alternative to traditional neuraxial interventions; the advantages of spinal or subarachnoid block are fused with the flexibility of the epidural technique; they offer a fast, effective and minimally toxic spinal block, improve inadequate block, and prolong the duration of anesthesia with epidural supplements.The purpose of this article is to report the case of a pregnant woman with a diagnosis of uncorrected Tetralogy of Fallot and the anesthetic technique of effective establishment without producing harmful hemodynamic changes for the mother-child binomial.
\end{abstract}

Keywords: combined spinal epidural technique, obstetric anesthesia, caesarean section, tetralogy of fallot uncorrected
Volume 12 Issue 6 - 202I

\author{
Ana Leslie Tijero Espinoza,' Dante Junior \\ Segura Pinedo, ${ }^{2}$ Sandoval Valiente Luis \\ Enrique $^{3}$ \\ 'Resident physician of the Department of Anesthesia,Analgesia \\ and Resuscitation, Federico Villarreal National University, Lima- \\ Peru \\ ${ }^{2}$ Anesthesiologist Physician of the Department of Analgesia \\ and Resuscitation Anesthesia of the INMP, Fellowship in \\ Obstetric Anesthesia by the World Federation Societies of \\ Anesthesiologists at the Bolivarian Clinic in Medellin Colombia, \\ DDAMOS Instructor, Member of the Peruvian Society of Pain \\ and Palliative Care, Peru \\ ${ }^{3}$ Chief Physician of the Surgical Center Service of the \\ Department of Anesthesia, Analgesia and Resuscitation, \\ Member of the Peruvian Society of Analgesia and Resuscitation \\ Anesthesia, Peru
}

Correspondence: Ana LTijero Espinoza, Resident physician of the Department of Anesthesia,Analgesia and Resuscitation. Federico Villarreal National University, Jr. Miroquesada 94I, Cercado de Lima-Peru, Tel Phone: 916676794. Email dr.juanpablo_108@hotmail.com

Received: November 28, 202| | Published: December 08, 2021

\section{Introduction}

Tetralogy of Fallot (TOF) is the most common form of cyanotic congenital heart defect, accounting for $10 \%$ of all cases, continuous advances in surgical techniques, these patients now reach childbearing age and often tolerate pregnancy relatively well. However, without surgical intervention, $70 \%$ of people with TOF die in the first decade and only about 3\% survive in the fourth decade. Therefore, presentation of uncorrected TOF in pregnancy is rare and presents a significant risk to both the mother and the neonate. ${ }^{1}$

Several risk stratification models have been published: the CARPREG risk score (CARdiac disease in PREGnancy), the ZAHARA risk score (Zwangerschap bij Aangeboren HARtAfwijkingen I) modified WHO classification (mWHO) and the New York Heart Association scale. (NYHA) ${ }^{2}$ A significant shift from general to regional anesthesia, primarily in developed countries, has been linked to a decrease in anesthesia-related mortality. Combined Spinal Epidural Anesthesia (ACEE) has great advantages in pregnant women in cesarean section surgery such as labor. The ACEE technique offers a fast, effective and minimally toxic spinal block, prolongs the duration of anesthesia with epidural supplements. ${ }^{3}$

There are several ways to carry out the ACEE block, their differences fundamentally lie in the puncture in one or two spaces with one or two needles. The choice of access to a single space is probably associated with a lower incidence of headache, epidural venipuncture, hematoma, infection, and technical difficulty when compared to access to two spaces. Although the two-space block carries less risk of producing an extended or total subarachnoid block, due to the greater distance between the foramen of the dura mater and the tip of the catheter. ${ }^{4}$

The present Case Report aims to present the management of a case of a pregnant patient with uncorrected Tetralogy of Fallot and to determine which Anesthetic Technique is safe in cesarean section surgery, thereby providing useful information for anesthetic management.

a. Resident Physician of the Department of Anesthesia, Analgesia and Resuscitation. Federico Villarreal National University. Lima Peru.

b. Anesthesiologist Physician of the Department of Analgesia and Resuscitation of the INMP, Fellowship in Obstetric Anesthesia by the World Federation Societies of Anesthesiologists at the Bolivarian Clinic in Medellin Colombia, DDAMOS Instructor, Member of the Peruvian Society of Pain and Palliative Care. Lima Peru.

c. Chief Physician of the Surgical Center Service of the Department of Anesthesia, Analgesia and Resuscitation, Member of the Peruvian Society of Anesthesia, Analgesia and Resuscitation. Lima Peru.

Quote as: Tijero AL, Segura DJ, Sandoval L. Anesthesia for Caesarean section in a patient with uncorrected Tetralogy of Fallot from the National Maternal-Perinatal Institute. Lima Peru. 


\section{Case report}

29-year-old primigravida, 37 weeks' gestation, history of uncorrected TOF, came to emergency in active phase labor, mild to moderate dyspnea.

Pre anesthetic evaluation: BMI of $20.65 \mathrm{~kg} / \mathrm{m}^{2}$, ASA III, CARPREG> 1, HR 76/min, RR 22/min, BP 122/63 mmHg. SO2 95\%, FiO2 21\%, oral opening $3 \mathrm{~cm}, \mathrm{TMD}>6 \mathrm{~cm}$, Mallampati III, FCF 144/min, RQ III, perioral cyanosis and nail bed, drumstick fingers and toes (Figure 1).

Cardiovascular: Sand he heard a single, loud second sound with a systolic murmur of the IV / VI pulmonary focus.

Ap. Respiratory: Vesicular murmur goes well in both lung fields, not rales.

\section{Laboratory exams:}

\begin{tabular}{lllll}
\hline Hb $13.2 \mathrm{~g} / \mathrm{dL}$ & TP $13.4 "$ & Platelets 283,000 & Glucose $73 \mathrm{mg} / \mathrm{dL}$ & Urea $17 \mathrm{mg} / \mathrm{dL}$ \\
Hto $40 \%$ & TTP $38.6 "$ & Fibrinogen $389 \mathrm{mg} / \mathrm{dL}$ & Creatinine $0.65 \mathrm{mg} / \mathrm{dL}$ & Proteins $6.20 \mathrm{~g} / \mathrm{dL}$ \\
\hline
\end{tabular}

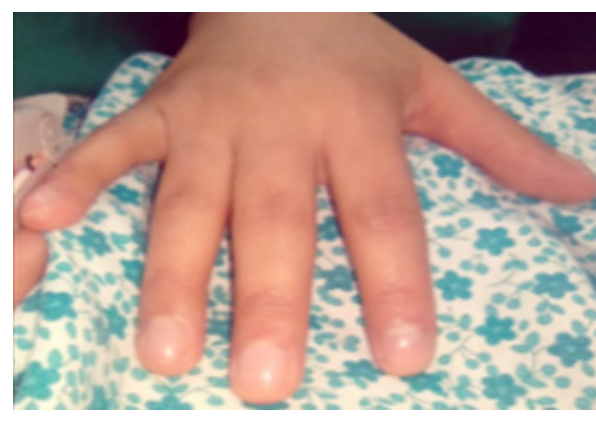

Figure I Pre anesthetic evaluation.

Echocardiogram: From the third trimester.

\begin{tabular}{|c|c|c|c|c|}
\hline $\begin{array}{c}\text { Fracción } \\
\text { de eyección } \\
65 \%\end{array}$ & $\begin{array}{c}\text { Tetralogía } \\
\text { de Fallot }\end{array}$ & $\begin{array}{c}\text { Función } \\
\text { sistólica } \\
\text { biventricular } \\
\text { conservada }\end{array}$ & $\begin{array}{c}\text { Derrame } \\
\text { pericárdico } \\
\text { moderado }\end{array}$ & $\begin{array}{c}\text { Cabalgamient } \\
\text { o de aorta }\end{array}$ \\
\hline $\begin{array}{c}\text { Estenosis } \\
\text { pulmonar }\end{array}$ & $\begin{array}{c}\text { Disfunción } \\
\text { diastólica } \\
\text { severa }\end{array}$ & $\begin{array}{c}\text { Crecimiento } \\
\text { de la aurícula } \\
\text { derecha } \\
\text { severa }\end{array}$ & $\begin{array}{c}\text { Hipertrofia } \\
\text { ventricular } \\
\text { derecha }\end{array}$ & CIV $6 \mathrm{~mm}$. \\
\hline
\end{tabular}

\section{Anesthetic technique}

Patient in DLI (Figure 2) skin infiltrates with 2\% lidocaine in L3L4 space, Touhy trocar \# 18 is inserted, with loss of resistance until reaching the epidural space, spinal trocar pencil tip \# 27 is inserted, Hyperbaric bupivacaine $5 \mathrm{mg}$ is administered. $0.5 \%$, Fentanyl 10 ug., Morphine 100 ug.,_Cephalic epidural catheter is inserted at 12 $\mathrm{cm}$, patient in supine position is administered Lidocaine $100 \mathrm{mg}$. $2 \%$ without epinephrine by epidural catheter; with needle after needle ACEE an adequate anesthetic level is achieved, surgery is started, a product of $2950 \mathrm{~kg}$ is obtained, with apgar 81 95, with volume restriction, with perfusion of $\mathrm{NaCl} 0.9 \% \mathrm{BHE}(-)$, during the intraoperative hemodynamics remained stable with minimal changes, postoperative in intermediate ICU for 24 hours, discharge from the service.

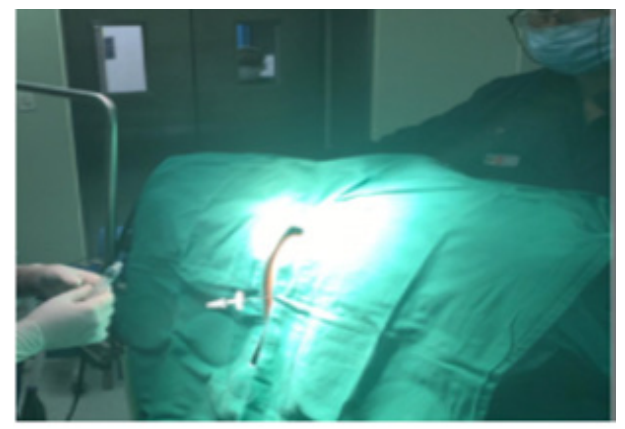

Figure 2 Patient in DLI skin infiltrates.

\section{Discussion}

Heart disease is emerging as the most important indirect cause of maternal death globally, it may be masked by an increased volume load, or it may be caused by pregnancy.Mortality data contextualize the risk of heart disease in pregnancy with fatality rates close to 1 in 200 , this compared to other obstetric complications that are considered high risk.

I knowIt stratifies the pregnant NYHA class III or IV with a predicted $27 \%$ event rate, taking into account the state of the pregnant woman with uncorrected TOF, pulmonary stenosis, and severe diastolic dysfunction.

The ACEE technique is used in obstetric practice in patients with heart disease to provide quality and efficacy analgesia and anesthesia, through the use of various drug combinations, reducing the requirements of anesthetic agents used, with minimal hemodynamic changes despite the changes. Physiological properties per se and blockade at lower doses of local spinal anesthetic reduces the risk of high spinal block and maternal hypotension. ${ }^{5}$

The advantage of this needle-through-needle technique with the patient in the left lateral decubitus position, avoids aorto-caval compression, the epidural catheter is used to complement the previous mapping spinal block in the patient and for postoperative analgesia.

Although the drugs cross the placenta and can be measured in the neonate, local anesthetics do not cause neonatal depression. ${ }^{6}$

\section{Conclusion}

ACEE turned out to be a safe technique for cesarean section in this patient with uncorrected TOF, with adequate sensory and motor blockade, with minimal hemodynamic changes; It did not aggravate a pre-existing cardiovascular condition, with better recovery and postoperative pain management.

\section{Recommendations}

Pre-anesthetic evaluation days prior to surgery for perioperative management.

Prophylactic use of vasopressors avoiding major hemodynamic changes.

No fluid overload and use of an epidural catheter for postoperative analgesia.

Gratitude: To all the people who make this case report possible.

\section{Acknowledgments}

None. 


\section{Funding}

None.

\section{Conflicts of interest}

None of the authors has reported any conflicts of interest.

\section{References}

1. Drenthen W, Boersma E, Balci A, et al. Predictors of pregnancy complications in women with congenital heart disease. Eur Heart J. 2010;31:2124-2132.
2. Van Hagen IM, Boersma E, Johnson MR, et al. Global cardiac risk assessment in the registry of pregnancy and cardiac disease. Eur J Heart Fail. 2016;18:523-533.

3. Van de Velde M. Combined spinal epidural analgesia for labor and delivery: a review. Acta Anaesthesiol Belg. 2004;55:177.

4. Hughes D, Simmons SW, Brown J, et al. Combined spinal-epidural. Cochrane Database Syst Rev. 2003;4:CD003401.

5. Ngan Kee WD. The use of vasopressors during spinal anesthesia for caesarean section. Curr Opin Anesthesiol. 2017;30:319-325.

6. Littleford J. Effects on the fetus and newborn of maternal analgesia and anesthesia: a review. Can J Anaesth. 2004;51:586-609. 